\title{
Erratum: Chromatin-associated degradation is defined by UBXN-3/FAF1 to safeguard DNA replication fork progression
}

André Franz, Paul A. Pirson, Domenic Pilger, Swagata Halder, Divya Achuthankutty, Hamid Kashkar, Kristijan Ramadan \& Thorsten Hoppe

Nature Communications 7:10612 doi: 10.1038/ncomms10612 (2016); Published 4 Feb 2016; Updated 17 May 2016

This Article contains errors in the labelling of Fig. 5 and Supplementary Fig. 6, the former of which was introduced during the production process. In Fig. 5b, an ' $x$ ' indicating the presence of UBXN-3(SGG)-HIS in lane 6 was inadvertently omitted. In Supplementary Fig. 6g, the fourth bar from the left should have been labelled as 'siFAF1 3'UTR \#2+HA-FAF1'. The correct version of both figures appear below.

a

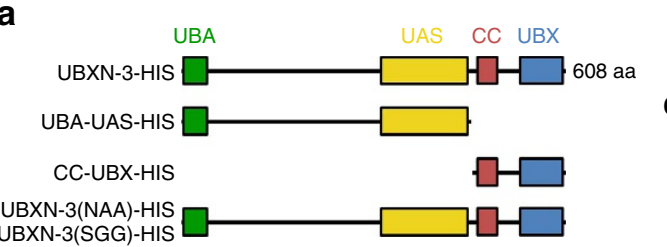

b

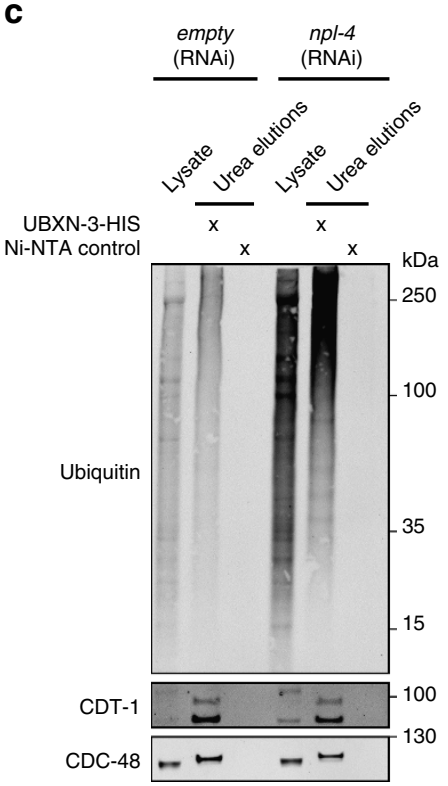

Figure 5 
a

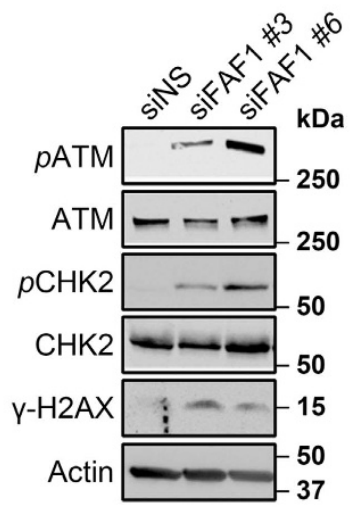

C

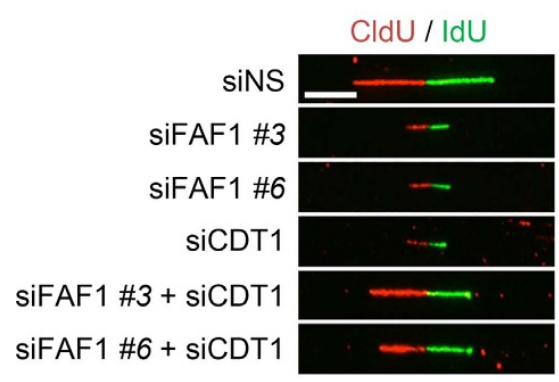

f

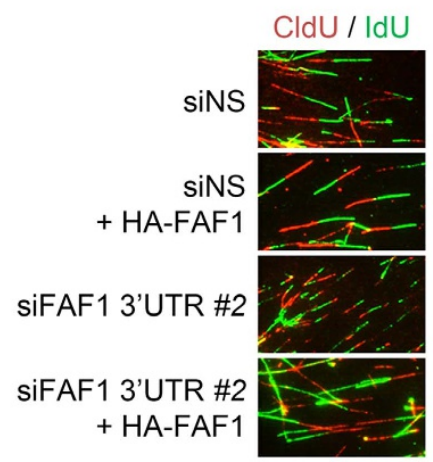

b

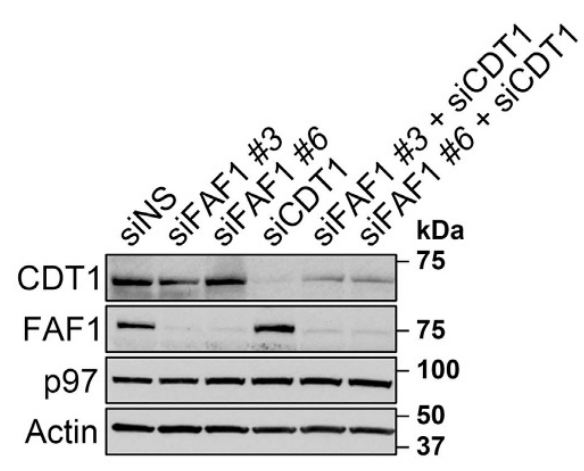

d

e

CldU / IdU

terminated forks
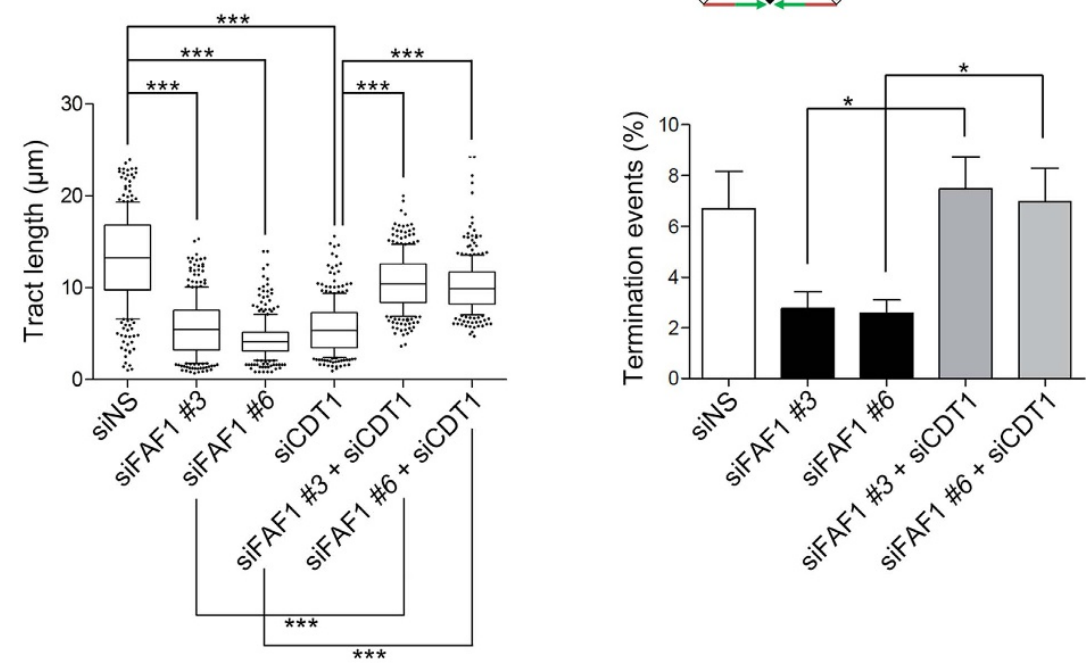

g

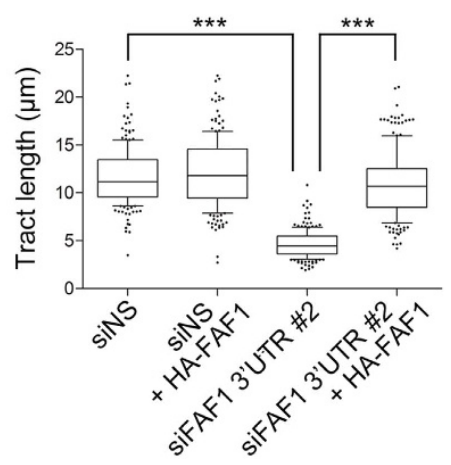

h

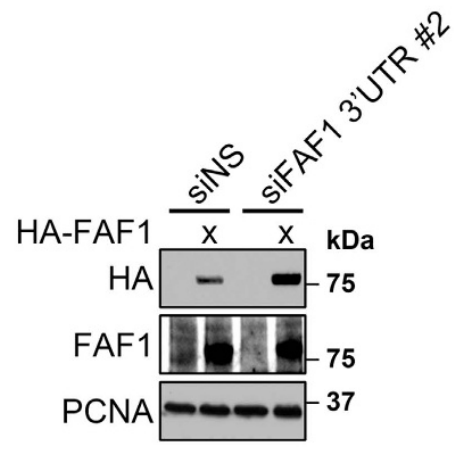

Supplementary Figure 6

(c) (i) This work is licensed under a Creative Commons Attribution 4.0 International License. The images or other third party material in this article are included in the article's Creative Commons license, unless indicated otherwise in the credit line; if the material is not included under the Creative Commons license, users will need to obtain permission from the license holder to reproduce the material. To view a copy of this license, visit http://creativecommons.org/licenses/by/4.0/ 